Article

\title{
Thermal Fatigue Properties of H13 Hot-Work Tool Steels Processed by Selective Laser Melting
}

\author{
Mei Wang ${ }^{1}\left(\mathbb{D}\right.$, Yan $\mathrm{Wu}^{2}$, Qingsong Wei ${ }^{1, *}$ and Yusheng Shi ${ }^{1}$ \\ 1 State Key Laboratory of Materials Processing and Die \& Mould Technology, School of Materials Science and \\ Technology, Huazhong University of Science and Technology, Wuhan 430074, China; \\ wangmei@hust.edu.cn (M.W.); shiyusheng@hust.edu.cn (Y.S.) \\ 2 Department of Industrial Engineering, University of Louisville, Louisville, KY 40292, USA; \\ y0wu0020@louisville.edu \\ * Correspondence: wqs_xn@hust.edu.cn; Tel.: +86-027-8755-8155
}

Received: 27 November 2019; Accepted: 9 January 2020; Published: 12 January 2020

\begin{abstract}
Currently, selective laser melting (SLM) is gaining widespread popularity as an alternative manufacturing technique for complex and customized parts, especially for hot-work and injection molding applications. In the present study, as the major factors for the failure of H13 hot-work die steels during hot-working, thermal fatigue (TF) properties of H13 processed by SLM and a conventional technique were investigated. TF tests $\left(650^{\circ} \mathrm{C} / 30^{\circ} \mathrm{C}\right)$ were conducted on the as-selective laser melted (As-SLMed), thermally treated selective laser melted (T-SLMed), and forged (Forged) H13. Results show that the As-SLMed H13 exhibited the best TF resistance properties among the specimens herein (the shortest total crack length and highest hardness of $687 \pm 12 \mathrm{HV}_{5}$ ), whereas the Forged $\mathrm{H} 13$ exhibited the poorest TF resistance properties (the longest total crack length and lowest hardness of $590 \pm 11 \mathrm{HV}_{5}$ ) after TF tests. TF resistance properties were closely related to the initial and final hardness. Further microstructural investigations revealed that the typical cell-like substructures, increased amount of retained austenite, and most importantly, refined grain size were the main reasons for the improved TF resistance properties in the As-SLMed H13 compared to the Forged counterparts.
\end{abstract}

Keywords: selective laser melting (SLM); tool steel; thermal fatigue; hardness; microstructure

\section{Introduction}

Additive manufacturing is a group of technologies that build near net-shape components by a track-by-track, layer-by-layer method. Selective laser melting (SLM) is a layer wise material addition technique that can generate complex 3D parts by selectively consolidating successive layers of powder materials on top of each other, using thermal energy supplied by a focused and computer-controlled laser beam [1-3]. SLM is also referred to as the laser powder bed fusion process (L-PBF) or laser beam melting (LBM) [1,4]. The competitive advantages of SLM include geometrical freedom and the ability to produce near-full density parts with high strength [5]. SLM processed metal parts are promising for various industrial applications, for instance, as aerospace components with an optimized geometry or lightweight structures, rapid tooling, and biomedical implants [5]. The other major advantage of SLM is the production of internal features and passages, especially in die casting and injection molding applications.

H13 tool steel ( $5 \%$ Cr hot-work die steel) is one of the most commonly used tool steels for casting and forging dies owing to its high-temperature strength and good temper resistance properties [6]. Generally, to obtain the required profile and mechanical properties, conventional die-making processes involve forging, annealing, computer numerically controlled (CNC) machining, electrical discharge machining 
(EDM), thermal treatments, grinding, and polishing [7]. The cooling channels of conventional dies are generally made by deep drilling and thus have the shape of the straight line. Obviously, this kind of cooling channel exhibits low cooling efficiency during the hot-working process [8]. Currently, SLM has received increasing attention in the hot-work mold field $[7,9,10]$. During the hot-working process, the SLM processed hot-work dies with integrated conformal cooling channels can allow a more effective and uniform heat transfer, thus reducing cycle time and improving the quality of the workpieces [10]. For instance, Hölker et al. [11] successfully designed and manufactured an extrusion die with integrated cooling channels by SLM, with the aim of increasing productivity during the aluminum extrusion process. Armillotta et al. [7] found that, compared to casting die with conventional straight-line cooling channels, SLM processed casting die with conformal cooling channels improved the surface finish of castings and reduced the cycle time and shrinkage porosity. Furthermore, the rapid solidification during SLM can ensure the formation of refined grains and enhanced mechanical properties of the SLM processed components compared to cast and forged counterparts [12]. Therefore, SLM is an alternative option for fabricating high-performance $\mathrm{H} 13$ hot-work dies.

Generally, the as-built SLM processed H13 exhibits the heavy alloying elements segregated as cell-like substructures in the martensite matrix $[13,14]$. Due to the different processing parameters, the mechanical properties of SLM processed H13 were largely scattered. Besides, high residual stresses and some remaining defects in SLM processed H13 resulting in reduced mechanical properties (such as cracking susceptibility, low elongation [15], and low fatigue strength [16]) compared to conventionally processed material [9]. Recently, efforts have been made to obtain high-quality H13 parts processed by SLM. These efforts primarily illustrated the effect of processing parameters and post treatment on the microstructures and mechanical properties of SLM processed H13. Laser power, scanning speed, scanning strategy, building orientation, and preheating treatment are the key processing parameters for the mechanical properties. Laakso et al. [17] applied the design of experiments (DOE) approach to optimize the laser power, scanning speed, and hatch width and established a parameter window for SLM of H13. Ren et al. [18] applied optimized laser power and scanning speed to obtain a high density of SLM processed H13 with a tensile strength of 1909 MPa and an elongation of $12.4 \%$. Kurzynowski et al. [19] found that scanning strategy significantly influences quantity, sizes, and arrangement of pores. Besides, the density of supports and their proper inclination can reduce the number of columnar pores. Holzweissig et al. [20] revealed the relationship between the processing parameters and microstructure evolution. The result showed that SLM processed H13 was predominantly made up of martensite and some retained austenite. They also indicated that the increased ductility for specimens tested parallel to building direction should be attributed to the tempering effect deduced by the repetitive heat flow to the building platform. During SLM, powder bed preheating is mainly applied to avoid large thermal stresses in the material [15]. Mertens et al. [15] revealed that preheating could result in the softening of the $\mathrm{H} 13$ when the temperature of the building platform was $200{ }^{\circ} \mathrm{C}$ and hardening it when it was $400{ }^{\circ} \mathrm{C}$ They indicated that fine bainitic microstructures accounted for the increased mechanical properties. Post treatment has been published as another major factor in the microstructure, porosity and mechanical properties of SLM processed H13. Åsberg et al. [21] illustrated that austenitizing treatment can eliminate solidified colonies of prior austenite and that hot isostatic pressing followed by heat treatment can improve the mechanical properties by reducing porosity and fusion defects. Deirmina et al. [14] revealed that the cellular/dendritic solidification structures were removed after quenching and were largely recovered after direct tempering at $650^{\circ} \mathrm{C}$. The fracture toughness was acceptable for SLM processed H13 specimens that after heat treatment. Other factors like raw materials and service condition of the final product (residual stress, porosity, oxygen content, textured microstructures, and surface roughness) can also exert some influence on the resulted properties [14,16,22].

However, thermal fatigue (TF), the main cause of die failure during hot working (accounting for $70 \%$ of the failures in die casting $[23,24])$, has not received enough attention for the SLM processed H13. During the hot-working process, the dies are repeatedly subjected to heating/cooling cycles and 
mechanical loads that develop from the close contact between tools and hot workpieces (for instance, the temperature of molten aluminum during casting is $\left.670-710^{\circ} \mathrm{C}\right)[25,26]$. Premature failures caused by TF degrade the quality of workpieces and increase the cost of dies significantly during the hot-working process [27]. Therefore, improving the resistance to TF of hot-work die steel is always a subject of major concern to engineers and researchers [28].

In the present study, the TF properties of H13 specimens fabricated by SLM were investigated and compared with the conventionally forged H13. X-ray diffraction (XRD), scanning electron microscopy (SEM) and electron backscattered diffraction (EBSD) techniques were used to reveal the reasons for the discrepancy in the TF properties between the additively and conventionally fabricated H13.

\section{Materials and Methods}

\subsection{Materials and Post Treatment}

For the SLM specimens, a prealloyed H13 powder was used. As shown in Figure 1a, the gas-atomized powders were nearly spherical, with the particle size of approximately $27.4 \mu \mathrm{m}$. The powders were fabricated into bulk materials by an SLM solution machine. The SLM process parameters were selected to obtain a relatively high density based on our previous work [13] and were fixed as follows: the layer thickness was $40 \mu \mathrm{m}$; laser power was $280 \mathrm{~W}$; scanning speed was $980 \mathrm{~mm} / \mathrm{s}$; scanning spacing was $120 \mu \mathrm{m}$; and laser scanning orientation of each layer was rotated by $67^{\circ}$ relative to the previous layer. The platform temperature was $90-93{ }^{\circ} \mathrm{C}$ during SLM. An argon atmosphere was maintained to prevent oxidation during the SLM process. The bulk materials were built as shown in Figure 1b. The obtained as-selective laser melted (As-SLMed) H13 had a hardness of $597 \pm 12 \mathrm{HV}_{5}$. The density was determined to be $7.754 \pm 0.0037 \mathrm{~g} / \mathrm{cm}^{3}$ according to the Archimedes method. No cracks have been detected. Nevertheless, large residual stress generally remains in the as-built parts and thus may lead to inferior toughness in the material. Yan et al. [29] revealed that high residual stresses in the range of 940-1420 MPa were detected in the as-built H13. Therefore, the SLM processed H13 that after a stress-relieving treatment was also investigated in this study. Then, the as-built specimens were treated by $2 \mathrm{~h}$ of tempering at $500{ }^{\circ} \mathrm{C}$, and then, another $2 \mathrm{~h}$ of tempering at $600{ }^{\circ} \mathrm{C}$. The obtained hardness was $599 \pm 8 \mathrm{HV}_{5}$. These thermally treated selective laser melted $\mathrm{H} 13$ specimens were referred to as "T-SLMed H13". DIEVAR (ASSAB Company) is a forged tool steel that is similar to H13 [30]. The forged specimens, made from DIEVAR, were solution treated for $30 \mathrm{~min}$ at $1020{ }^{\circ} \mathrm{C}$, oil quenched and double tempered at $510{ }^{\circ} \mathrm{C}$ for $2 \mathrm{~h}$ to obtain a hardness equal to that of the other two materials. The treated forged specimens were referred to as "Forged H13" and had a hardness of $595 \pm 9 \mathrm{HV}_{5}$. The density was determined to be $7.760 \pm 0.0063 \mathrm{~g} / \mathrm{cm}^{3}$ according to the Archimedes method. No cracks have been detected. The T-SLMed and Forged H13 specimens were thermally treated to a hardness similar to the As-SLMed H13, that is because TF resistance is closely related to the initial hardness [26]. The chemical compositions of the SLM processed and Forged H13 are shown in Table 1. The Forged H13 had a lower amount of Si than the SLM processed H13, which was regarded as an effective method to improve the toughness properties of H13 material [31]. In addition, V has a detrimental effect on toughness, and Mo can lead to grain refinement without sacrificing the toughness in martensitic steels [32,33]. Therefore, DIEVAR was used as the forged counterparts to SLM processed H13 because it possessed the increased amount of Mo and the decreased amount of Si and V. Chemical compositions were determined by the methods that were used in reference [13]. Density, hardness, and heat treatment methods of the three different materials are given in Table 2.

Table 1. Chemical compositions of the different H13 steel materials (weight percent).

\begin{tabular}{cccccccc}
\hline Material Type & $\mathbf{C}$ & Cr & Mo & Si & V & Mn & Fe \\
\hline SLMed H13 & 0.37 & 5.05 & 1.32 & 1.11 & 1.07 & 0.49 & Bal. \\
Forged H13 & 0.39 & 4.80 & 2.4 & 0.24 & 0.55 & 0.50 & Bal. \\
Tolerance ( \pm ) & 0.005 & 0.035 & 0.024 & 0.020 & 0.020 & 0.015 & \\
\hline
\end{tabular}


Table 2. Experimental work data of the used materials.

\begin{tabular}{cccc}
\hline Material Type & Density $\mathbf{( g / \mathbf { c m } ^ { 3 } )}$ & Hardness $\mathbf{( \mathbf { H V } _ { \mathbf { 5 } } )}$ & Heat Treatment Methods \\
\hline $\begin{array}{c}\text { As-SLMed } \\
\text { T-SLMed }\end{array}$ & $7.754 \pm 0.0037$ & $597 \pm 12$ & $\begin{array}{c}\text { As-built condition } \\
\text { Tempering at } 500{ }^{\circ} \mathrm{C} / 2 \mathrm{~h} \text { and then } \\
\text { tempering at } 600{ }^{\circ} \mathrm{C} / 2 \mathrm{~h}\end{array}$ \\
Forged & $7.754 \pm 0.0037$ & $599 \pm 8$ & $\begin{array}{c}\text { Solution treatment at } 1020^{\circ} \mathrm{C} / 30 \mathrm{~min} ; \\
\text { oil quenching; double tempering at } \\
510^{\circ} \mathrm{C} / 2 \mathrm{~h} \text {; air cooling }\end{array}$ \\
\hline
\end{tabular}
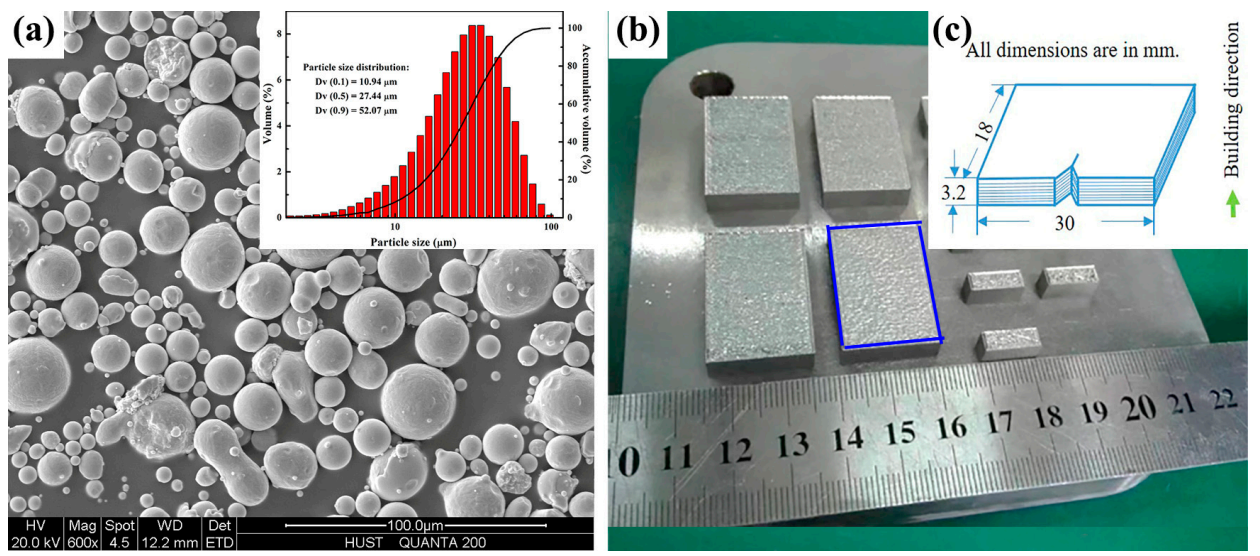

Figure 1. (a) Powders for the selective laser melting (SLM) process. (b) Bulk materials after the SLM process. (c) The profile of specimens for thermal fatigue (TF) tests.

\subsection{Fatigue Testing}

TF tests were carried out by a self-made machine, as shown in Figure 2a. The specimen was handled by a steel trap with the V-notch opposite to the water pipe. The specimen was heated by an electromagnetic induction coil, and the current was adjusted to make sure the temperature could rise to $650{ }^{\circ} \mathrm{C}$ within $3 \mathrm{~s}$. The heating time was set to only $3 \mathrm{~s}$. That is because hot-work dies are generally heated by the contact of hot work pieces, so the temperature of dies increases rapidly. The temperature of $650{ }^{\circ} \mathrm{C}$ was calibrated by a standard thermocouple, and the testing position was near the tip of the crack source. Then, the specimen was cooled to $30^{\circ} \mathrm{C}$ within $6 \mathrm{~s}$ by using running water. During TF tests, the machine could run the heating and cooling cycles according to the preset parameters automatically. Meanwhile, cycle times are recorded accordingly. A typical cycle for TF tests was $3 \mathrm{~s}$ for heating to $650{ }^{\circ} \mathrm{C}$ and $6 \mathrm{~s}$ for cooling to $30^{\circ} \mathrm{C}$. Figure $2 \mathrm{~b}$ is the picture of the specimen taken during the TF tests. Specimens for TF tests were machined by a low-speed wire electrical discharge machining (WEDM) using a Cu wire of $0.20 \mathrm{~mm}$ diameter from the bulk materials to form $30 \mathrm{~mm} \times 18 \mathrm{~mm} \times 3.2 \mathrm{~mm}$ specimens with a preset notch, as shown in Figure 1c. The notch was an isosceles right triangle with a length of $2 \mathrm{~mm}$ in the long edge and a crack source with a length of $1.5 \mathrm{~mm}$ and a width of $0.2 \mathrm{~mm}$ at the end of the right triangle. Specimens were ground to remove the top $0.15 \mathrm{~mm}$ and polished using 2000 grade silicon carbide impregnated emery paper to remove the rough surface layer (the morphology of a polished specimen was shown in Figure 2c). The TF tests were interrupted every 500 cycles to record the crack and measure the hardness. Before these tests, a 1000 grade polishing treatment was used for these specimens. The crack was observed by using an optical microscope (BL-SM1000, BELONA Corporation, Jinhua, China), and the hardness was measured by a Vickers hardness tester (432 SVD, Wolpert Wilson Instrument, Shenzhen, China) with a load of $5 \mathrm{~kg}$ over $15 \mathrm{~s}$. All hardness tests were conducted on the surface, which was perpendicular to building direction. As shown in Figure 2d, the dashed ellipse areas were chosen as the position for hardness identification because these dashed areas undergo $650{ }^{\circ} \mathrm{C}$ during tests. Six measuring points were used for hardness identification. The mean hardness values and standard deviation were 
calculated, which were used to plot the curves for hardness evolution with different testing cycle. Since thermal stresses concentrated in the front of the preset crack source during TF tests. Cracks developed when the stress is larger than the tensile stress of the material. Each crack branch means the release of the stress developed during TF tests. Therefore, total crack length was used to introduce the development of the cracks during TF tests. Total crack length used in the study is equal to the sum of each crack branch length. Three specimens were used for TF tests for each type of material.

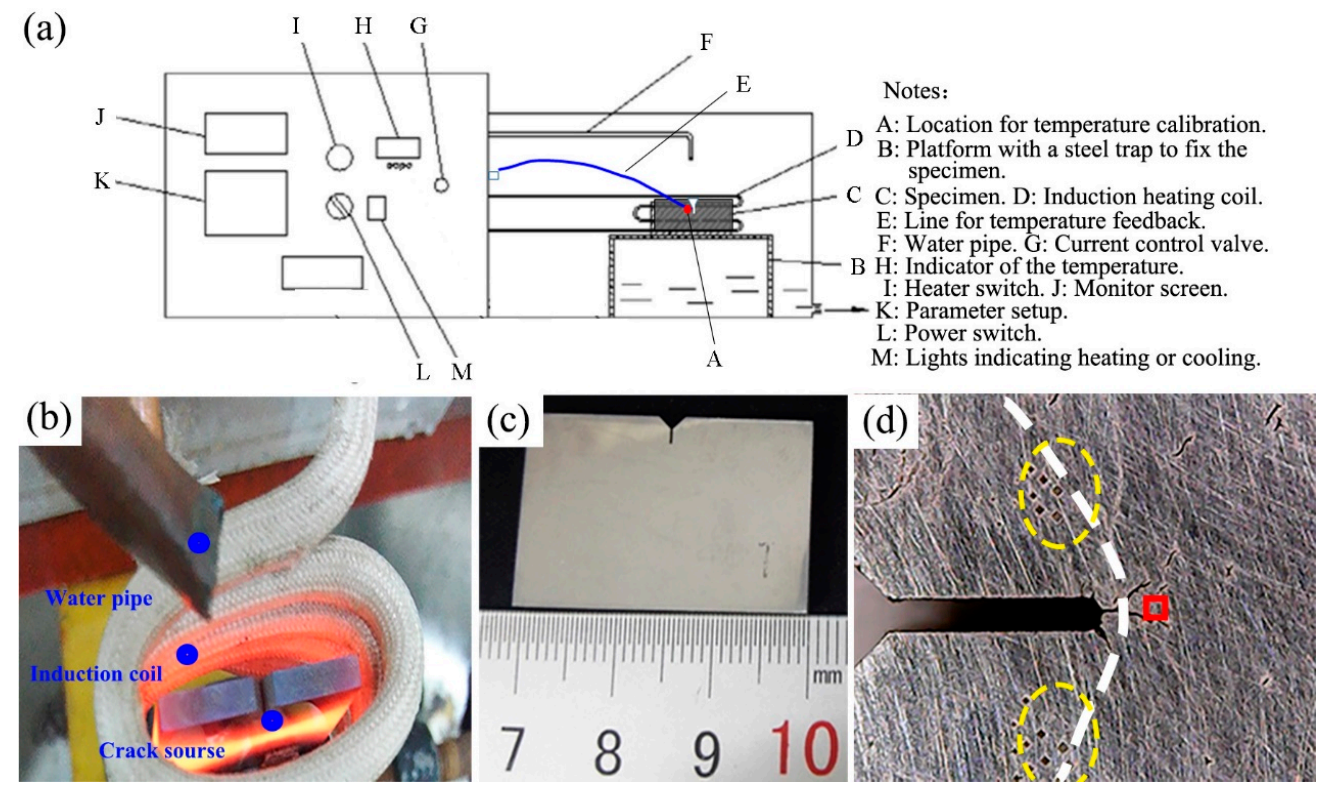

Figure 2. (a) Sketch of TF testing machine. (b) Specimen photo during TF tests. (c) Specimen for the TF test. (d) Photograph that indicates where the hardness indentations were performed.

\subsection{Materials Characterization}

SEM and XRD investigations were carried out before TF tests to identify the microstructural morphology and phase compositions of the three materials. The microstructures before TF tests were investigated by scanning electron microscopy (Quanta 650 FEG, FEI Company, Hillsboro, OR, USA). The microstructures after TF tests were investigated by scanning electron microscopy (GeminiSEM300, Carl ZEISS, Oberkochen, Germany). The location for microstructure observation after TF tests was $330 \mu \mathrm{m}$ in front of the crack source. Before SEM observation, specimens were etched with corrosive liquid (30 mL of saturated picric acid with 3-4 drops of hydrochloric acid and 1 drop of detergent) at $80{ }^{\circ} \mathrm{C}$ for $20-60 \mathrm{sec}$. Phase identification was performed with an XRD instrument (XRD-7000s, Shimadzu Corporation, Kyoto, Japan) with $\mathrm{Cu} \mathrm{K} \alpha$ radiation at $40 \mathrm{kV}$ and $40 \mathrm{~mA}$. Specimens for EBSD tested were prepared by an electrolytic polish machine (LectroPol-5, Struer Als, Ballerup, Denmark) with A2 reagent (vol 10\% perchlorate, vol 90\% ethanol) at $20 \mathrm{~V}$ for $300 \mathrm{~s}$. The EBSD data were collected by an EDAX system, which was mounted on a scanning electron microscopy (Sirion 200, FEI Company, Eindhoven, the Netherlands) and the step size was $0.12 \mu \mathrm{m}$. For the As-SLMed H13 specimens, the surface for EBSD analysis was perpendicular to the building direction. EBSD before TF tests was conducted at the location in the middle of two laser tracks. EBSD after TF tests was conducted at the location that was $330-400 \mu \mathrm{m}$ in front of the crack source.

\section{Results}

\subsection{Phase Analysis}

As shown in Figure 3a, the As-SLMed H13 possessed $\alpha$ and $\gamma$ phases. However, the T-SLMed and Forged H13 comprised only the $\alpha$ phase. Further EBSD analysis identified that the volume fraction 
of retained austenite in the As-SLMed specimens was approximately $11.5 \%$ (Figure 3b). However, there was little austenite retained in the T-SLMed and Forged H13. The larger amount of austenite retained in the As-SLMed H13 should be attributed to the following reasons. (i) The solubility of $\mathrm{C}$ in austenite is greater than that in ferrite because of the larger interstices available. During the martensite transformation process, some austenite can be stabilized by carbon diffusion from the carbon supersaturated martensite into the austenite [34]. (ii) An elevated temperature of the building platform (deduced by the heating effect of the lasers during the SLM process) led to the process being finished far from the martensite finish temperature [20]. (iii) The fast cooling rate during the SLM process resulted in a high fraction of retained austenite [35]. The reasons for the small amount of austenite retained in the T-SLMed and Forged H13 could be that the retained austenite was transformed to $\alpha$-iron during the tempering treatment process [13].
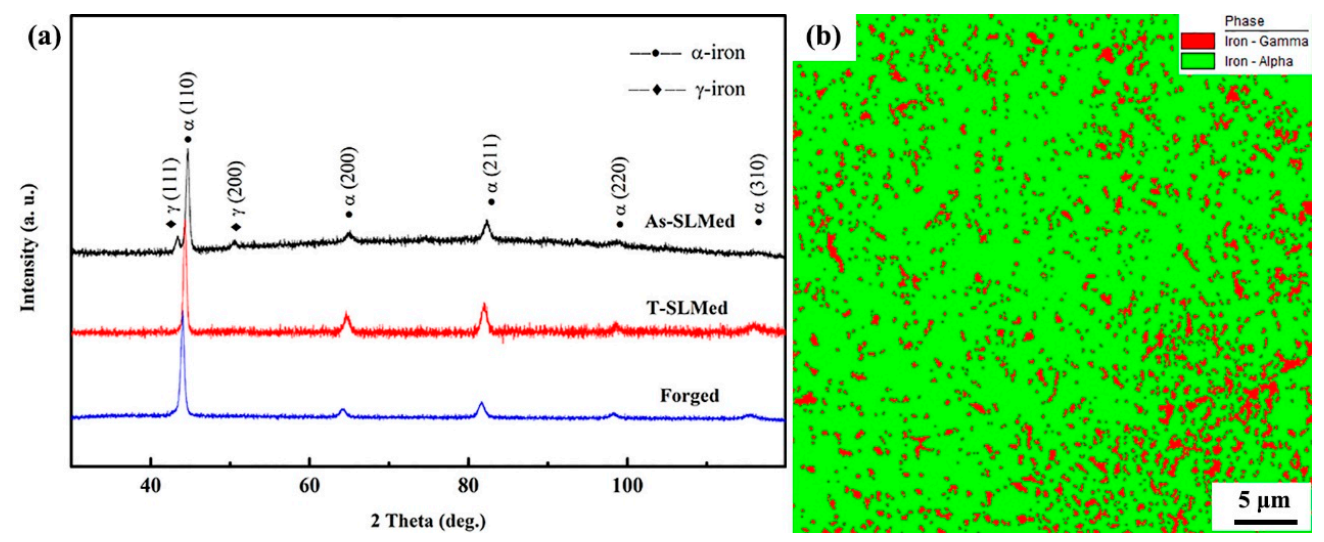

Figure 3. Phase characterization before TF tests. (a) XRD spectra of the as-selective laser melted (As-SLMed), thermally treated selective laser melted (T-SLMed), and Forged H13. (b) Phase distribution image of the As-SLMed H13 before the TF test.

Figure 3a shows that the $2 \theta$ angles of the (110) peaks from the $\alpha$ phase in the As-SLMed, T-SLMed, and Forged $\mathrm{H} 13$ were 44.7, 44.4, and 44.0, respectively. The relation of $2 \theta$ and the lattice plane spacing obeys the Bragg's law [36]:

$$
2 d \cdot \sin \theta=n \lambda,(n=1,2,3, \ldots),
$$

where $d$ is the lattice plane space, $\theta$ is the diffraction angle, $\lambda$ is the wavelength, and $n$ is the diffraction order. According to Bragg's law, a large $2 \theta$ means a small lattice plane spacing when $n$ and $\lambda$ are fixed. Therefore, the Forged H13 had the largest lattice plane spacing among the specimens herein, while the As-SLMed H13 had the smallest spacing. This could be explained by the following reasons. First, the As-SLMed H13 had the highest amount of retained austenite among the specimens herein. The higher solubility of $C$ in retained austenite than that in ferrite would lead to less amount of $C$ in $\alpha$ ferrite matrix of the As-SLMed H13. The carbon atoms entered the $\alpha$-iron lattice as interstitial solute atoms [34] and thus increased the lattice spacing. Therefore, according to Bragg's law, the $2 \theta$ values of (110) peak for the As-SLMed H13 would increase because less amount of $\mathrm{C}$ remained in the $\alpha$-iron of the material resulting in less increase of lattice spacing compared with the other two materials. Second, the heavy elements $(\mathrm{Cr}, \mathrm{Mo}$, and $\mathrm{Si}$ ) could diffuse and enter into the $\alpha$-phase lattice as substitutional atoms during the tempering treatment [13], resulting in an increase of the lattice spacing for T-SLMed and Forged H13. Due to the solution treatment, the alloying elements in the Forged H13 were more fully dissolved into the matrix than the other two materials, resulting in an increase of the lattice spacing of Forged H13. Third, after quenching and tempering treatment, the microstructure of Forged $\mathrm{H} 13$ was homogeneously consisting of tempered martensite with the dispersion of very fine secondary carbides [14]. Therefore, the precipitation of $C$ and carbides elements should lead to the decreasing of 
lattice spacing for Forged H13. Other factors such as grains size, residual stresses, and thermal history may also influence the lattice spacing.

\subsection{Microstructural Investigation}

Figure 4 shows the SEM images of the As-SLMed, T-SLMed, and Forged H13 before TF tests. Due to the track-by-track laser melting process of SLM, the as-built H13 generally revealed the typical morphology of molten pool boundaries [13]. The microstructure of the SLM processed H13 consists of cellular/dendritic structures [13,14,29]. As show in Figure 4a,b (viewed perpendicular and parallel to the building direction, respectively), the As-SLMed H13 exhibited epitaxial growth of the cellular dendrites along the fusion line. However, according to the work of Dilip [37] and our previous investigation [13], these cell-like substructures were not grains but anti-corrosive elements. These typical SLM network substructures were generally deduced by the slow kinetics of the large, heavy atoms during the rapid solidification of the SLM process [38]. By using the EBSD phase map, Deirmina et al. [14] found that retained austenite presented at the cellular boundaries because of the intercellular micro-segregation of alloying elements. Figure 4c reveals that the T-SLMed H13 had a similar morphology to that of the As-SLMed H13. In spite of this, it was found that some cell-like substructures were melted due to the thermally treated process, which was in accordance with our previous work [13]. Figure 4d shows that Forged H13 exhibited the tempered martensite microstructure. That is because the hardening and tempering treatments can produce tempered martensite with a high density of dislocations and secondary carbides for H13 material [39]. Obvious carbides have been observed as shown in Figure 4d. The energy dispersive X-ray (EDX) spectrum of the marked point " $\mathrm{A}$ " in Figure $4 \mathrm{~d}$ shows that the white precipitates were carbides that were composed of $\mathrm{C}, \mathrm{Cr}$, Mo, and V with a wt pct of 11.96, 3.5, 1.31, and 5.72 pct, respectively. Therefore, it can be deduced that these carbides were $\mathrm{V}$ rich carbides.
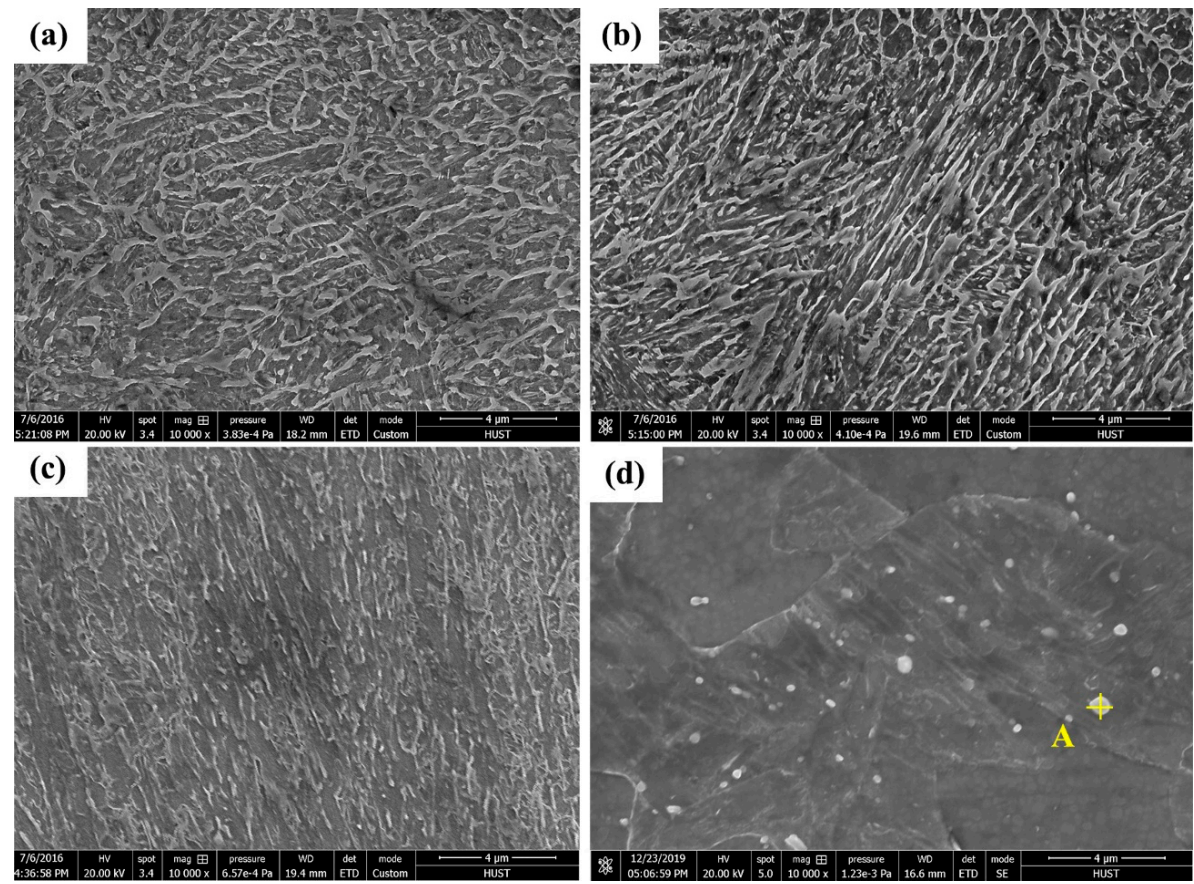

Figure 4. SEM images of the (a) As-SLMed part viewed perpendicular to the building direction and (b) As-SLMed part viewed horizontal to the building direction; (c) T-SLMed part viewed parallel to the building direction; and (d) Forged H13 part that before TF tests.

To further investigate the microstructure, EBSD was conducted on the As-SLMed H13 specimen, and the results are presented in Figure 5. The inverse pole figure (IPF) map of Figure 5a reveals a typical martensite microstructure with a three-level hierarchy in its morphology: martensitic laths, blocks, 
and packets [40]. The block size was approximately $1.43 \mu \mathrm{m}$. The grain boundary misorientation map of Figure $5 \mathrm{~b}$ indicates that the fraction of low-angle boundaries (in the range of $2-5^{\circ}$ ) was approximately $21.6 \%$. The high fraction of low angle boundaries signify high dislocations density within martensitic laths and in turn contribute to high strength in the material $[37,41]$.
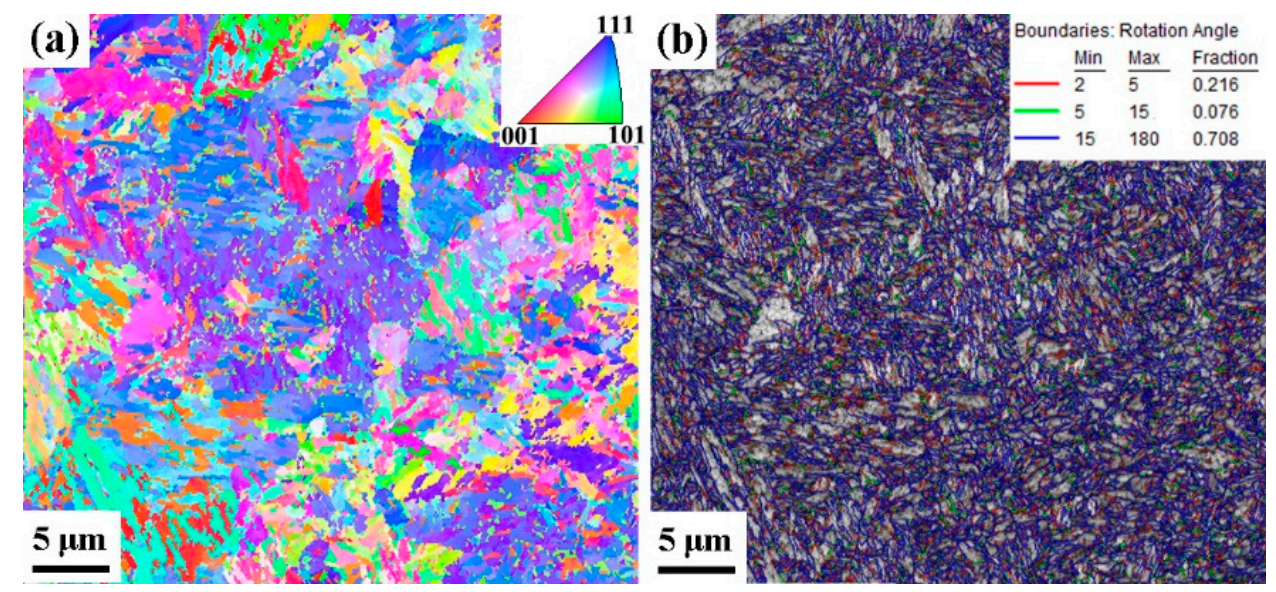

Figure 5. Electron backscattered diffraction (EBSD) of the As-SLMed H13. (a) Inverse pole figure map. (b) Grain boundary misorientation map.

Microstructures after TF tests were given in Figure 6. It was found that the Forged H13 revealed typical lath martensite microstructures, as shown in Figure 6a. The carbides (ballings in the circle B of Figure 6a) possessed higher amount of $\mathrm{V}$ and less amount of $\mathrm{Cr}$ in chemical compositions, while the particle size was the same size as that of the Forged H13 before TF, as shown in Figure 6d. That means carbides in Forged H13 became more in rich of V element. As shown in Figure 6b,c, the As-SLMed H13 exhibited similar morphology with the T-SLMed H13. Typical cell-like substructures and the molten pool boundaries disappeared after TF tests. The white particles (indicated by circle C) in Figure $6 \mathrm{~b}$ revealed the oxides presented in the SLM processed H13, as illustrated in Figure 6d. However, no obvious carbides can be observed in the As-SLMed and T-SLMed H13.
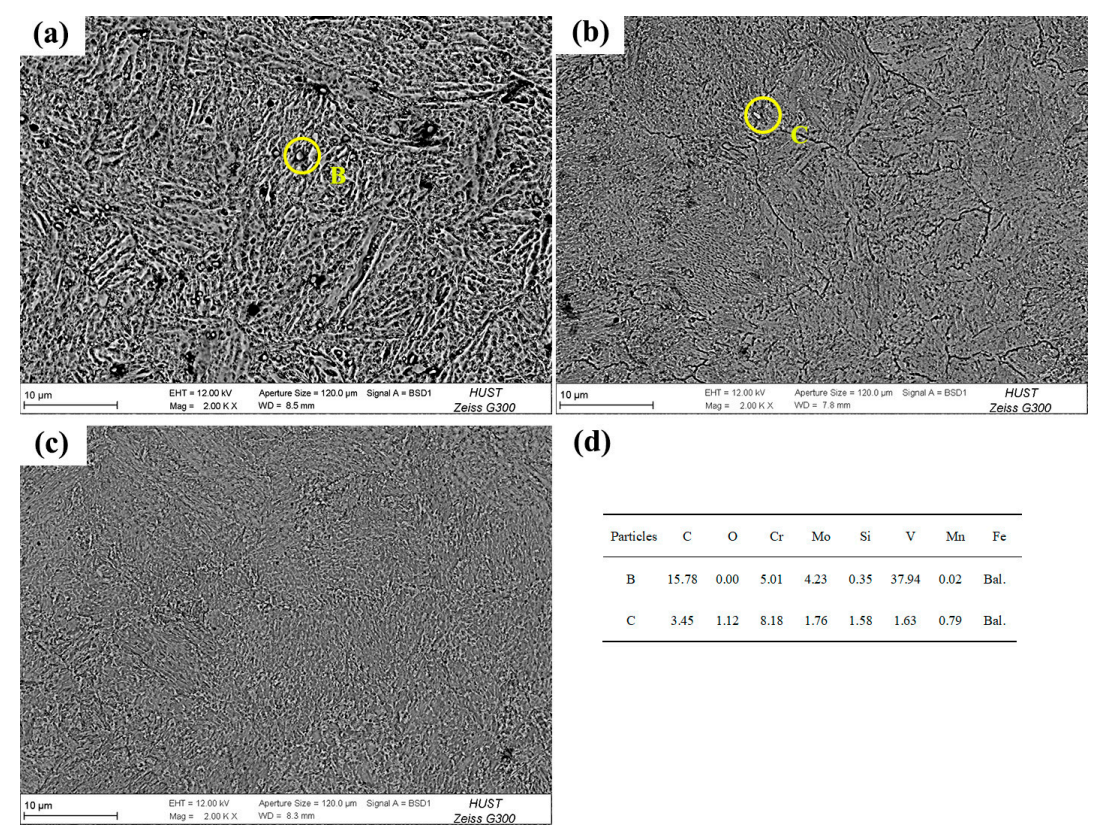

Figure 6. SEM images of the (a) Forged (b) As-SLMed, and (c) T-SLMed part after TF tests. (d) Chemical compositions of the indicated particles. 


\subsection{TF Properties}

Figure 7 shows the crack of the As-SLMed, T-SLMed, and Forged H13 specimens after different numbers of TF testing cycles. The total crack length were calculated and showed in Figure 8a. Among the tested specimens, the Forged H13 exhibited the longest total crack length, whereas the As-SLMed H13 exhibited the shortest total crack length after all cycles of the tests, except the 250 cycles. Mellouli et al. [26] illustrated that the increases in the hardness of H13 lead to the decreases in the crack growth rate. Their results were in accordance with this study that the Forged H13 exhibited the longest crack length and revealed the lowest hardness among the three materials, and the As-SLMed H13 exhibited the shortest crack length and revealed the highest hardness (as shown in Figure 8b). Therefore, TF resistance of $\mathrm{H} 13$ material is closely related to the initial and final hardness. For 250 cycles, the Forged H13 exhibited the shortest total crack length should be attributed to the stress relief effect during tempering treatment. Whereas the As-SLMed H13 possessed shorter crack length than the T-SLMed H13 should be attributed to the plastic properties of the retained austenite in the material.

(a)

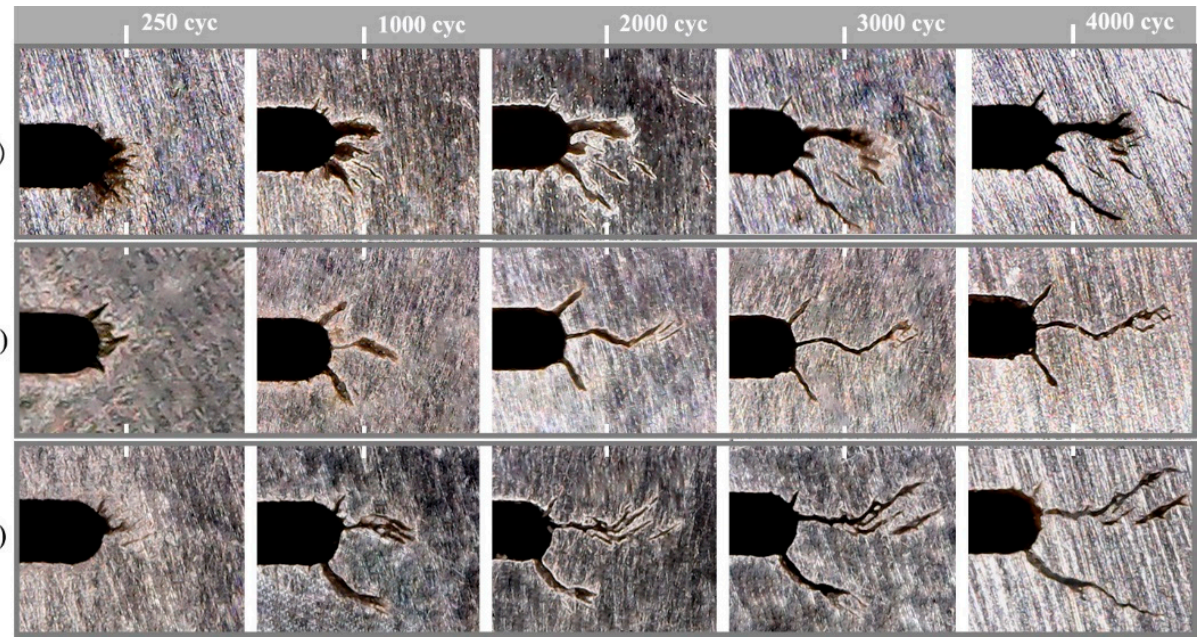

Figure 7. Crack images of the (a) As-SLMed, (b) T- SLMed, and (c) Forged H13 after different numbers of TF testing cycles.
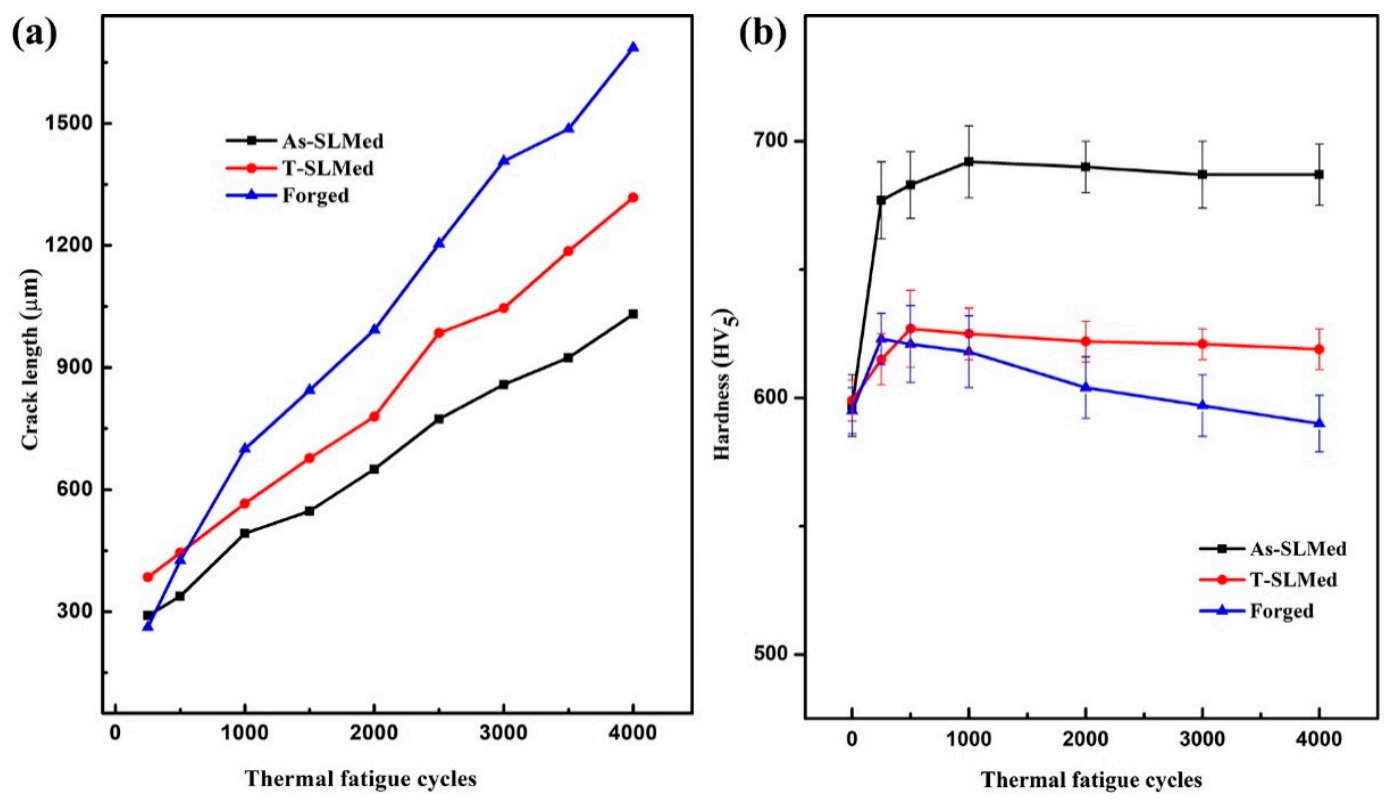

Figure 8. (a) Crack length and (b) microhardness of the As-SLMed, T-SLMed, and Forged H13 after different numbers of TF testing cycles $\left(650^{\circ} \mathrm{C} / 30{ }^{\circ} \mathrm{C}\right)$. 
Figure $8 \mathrm{~b}$ shows the hardness of the specimens after different numbers of TF testing cycles. Although all specimens had an initial hardness of approximately $597 \mathrm{HV}_{5}$, the hardness of the As-SLMed H13 increased sharply to $677 \pm 15 \mathrm{HV}_{5}$ within 250 cycles, then increased steadily to $692 \pm 14 \mathrm{HV}_{5}$ within 1000 cycles and held that value after 4000 cycles. The hardness of the T-SLMed $\mathrm{H} 13$ increased steadily to $627 \pm 15 \mathrm{HV}_{5}$ within 500 cycles and decreased steadily to $619 \pm 8 \mathrm{HV}_{5}$ after 4000 cycles. For the Forged H13, the hardness increased to $623 \pm 10 \mathrm{HV}_{5}$ within 250 cycles and then decreased steadily to $590 \pm 11 \mathrm{HV}_{5}$ after 4000 cycles. Therefore, it can be concluded that the As-SLMed and T-SLMed specimens showed obvious secondary hardening characteristics during the TF tests, while the Forged specimens showed some softening behavior.

\section{Discussion}

\subsection{Hardness Evolution during TF Testing}

Hardness is one of the most characteristic properties of materials [42]. As indicated in the ASM (American Society of Metals) brochure [32], the hardness decreases when the forged H13 is tempered at a temperature higher than that of the secondary hardening peak (approximately $525^{\circ} \mathrm{C}$ ). Therefore, the conventionally forged $\mathrm{H} 13$ materials cannot withstand temperatures higher than $525^{\circ} \mathrm{C}$, which have been illustrated in the work of Meng et al. [6]. They indicated that the hardness of traditional $\mathrm{H} 13$ (referred) decreased from approximately $500 \mathrm{HV}_{0.2}$ to approximately $430 \mathrm{HV}_{0.2}$ after $4000 \mathrm{TF}$ testing cycles $\left(650^{\circ} \mathrm{C} /\right.$ room temperature) [6]. However, the results herein show that all three materials exhibited higher hardness than the traditionally forged $\mathrm{H} 13$ after $4000 \mathrm{TF}$ testing cycles $\left(650^{\circ} \mathrm{C} / 30^{\circ} \mathrm{C}\right)$. Besides, the Forged $\mathrm{H} 13$ studied herein exhibited hardness higher than that of the traditionally forged $\mathrm{H} 13$ after TF testing. This should be mainly attributed to the different chemical composition in the two materials. Silicon has been reported to retard the cementite dissolution and promote the formation of alloy carbides at lower tempering temperatures. As a result, the secondary hardening peak of the low silicon material was shifted towards higher temperature [31]. Furthermore, the lower amount of $\mathrm{Cr}$ and higher amount of Mo can stabilize the $\mathrm{MC}$ and $\mathrm{M}_{2} \mathrm{C}$ carbides over the higher temperature range and delay their transformation to $\mathrm{M}_{23} \mathrm{C}_{6}$ [43]. As a result, a lower amount of $\mathrm{Si}$ and $\mathrm{Cr}$, and a higher amount of Mo can shift the secondary hardening peak towards higher temperatures and improve softening resistance [43], resulting in higher hardness in the Forged H13 compared to conventionally forged counterparts. Besides, the different initial hardness and thermal treatment history should also be taken into consideration.

The hardness of the Forged H13 increased first then decreased gradually should attribute to the following reasons. (i) The Forged $\mathrm{H} 13$ experienced the quenching and tempering treatment, and the tempering temperature of $500{ }^{\circ} \mathrm{C}$ was lower than the secondary hardening peak temperature [32]. Therefore, further hardness increase could be developed when further heat treatment was conducted. (ii) Fast cooling speed deduced by the cooling water during TF testing can facilitate the formation of martensite, and thus, the increase in the hardness. (iii) The formation of carbides is a diffusion-controlled process depending upon the tempering temperature and holding time. Tinny carbides precipitated when tempering was below $525^{\circ} \mathrm{C}$, which may lead to the increase of the hardness and result in secondary hardening [32]. It was published that no change in carbides morphology and size when tempering at $550{ }^{\circ} \mathrm{C}$, whereas the coarsening of carbides happened when treated with longer holding time at $600{ }^{\circ} \mathrm{C}$, which could result in the softening effect [43]. Therefore, the increase of the cycle numbers leads to the increase of thermally treated time of material and may lead to the carbides precipitated from tinny carbides to coarsening carbides during TF testing. However, in the present study, carbides after TF tests remained fine while the chemical compositions (Figure 6d) transformed, with the content of $\mathrm{C}, \mathrm{Mo}$, and $\mathrm{V}$ increased largely, indicating the precipitation of MoC and VC carbides during TF tests. The Mo and V carbides are more stable than Cr-rich carbides when treated at higher temperature [43], and thus, the hardness could maintain at a high level for the Forged H13 after TF tests. (iv) With further precipitation of carbides, the relatively hard and alloying rich $\alpha$-iron transformed 
towards to a soft and less alloying supersaturated state [43]. (v) Dislocation density reduces when the material was treated above the secondary hardening peak temperature, and thus, resulting in a hardness decrease. (vi) Relaxation of highly distorted supersaturated martensite and precipitation of transition carbides from the martensite decreased the hardness [43]. Therefore, the precipitation of $\mathrm{Mo} / \mathrm{V}$-rich carbides and fast cooling treatment during TF tests were the main reasons for the increase in hardness, while the transformation to the soft and less alloying-rich $\alpha$-iron result in the decrease in hardness.

The hardness of the As-SLMed H13 increased first then slightly decreased. This should attribute to the following reasons. (i) As shown in Figure 9a, no significant austenite was retained in the As-SLMed H13 after the TF tests. Deirmina et al. [14] indicated that the decomposition of retained austenite was responsible for the pronounced secondary hardening of the as-built SLM processed H13 when tempering at elevated temperatures. Therefore, the transformation of soft austenite into hard ferrite and/or fine carbides should lead to an increase in the hardness [14]. (ii) Our previous investigations [13] revealed that the hardness of the as-built SLM processed H13 increased all the time when tempering for $12 \mathrm{~h}$ at $500{ }^{\circ} \mathrm{C}$. Retained austenite had not been detected by XRD after $2 \mathrm{~h}$ tempering, whereas the network substructures dissolved all the time. Therefore, the retained austenite only function at the early stage. And the dissolution of cell-like substructures that were rich in Si, Mo, and V into the matrix during tempering should lead to an increase in the lattice spacing, and thus, the hardness had a further increase [13]. For the present study, it was found that the curve of the As-SLMed H13 during TF testing was similar to the secondary hardening curve of the as-built SLM processed H13. The TF testing process was similar to the tempering treatment. Therefore, the dissolution of network substructures into the matrix (Figure 6a) can result in the increase of hardness for the As-SLMed H13 during TF tests. (iii) The common secondary hardening mechanism for H13 is the precipitation of secondary carbides. However, secondary precipitated carbides were not found in the As-SLMed and T-SLMed H13, which can be explained as follows. Deirmina et al. [14] indicated that cell-like substructures can be observed after tempering at $600{ }^{\circ} \mathrm{C}$, and continuous network of carbides precipitated along the prior molten pool boundaries in the meantime. Besides, secondary carbides distribution within the martensite precipitated and remained fine and homogenous after tempering at $650{ }^{\circ} \mathrm{C}$. Their dilatometric tests proved that carbides could precipitate above $620{ }^{\circ} \mathrm{C}$ for the as-built H13 [14]. Furthermore, the homogeneous tiny carbides were also observed after $12 \mathrm{~h}$ of tempering at $600{ }^{\circ} \mathrm{C}$ in our previous investigation [13]. Therefore, precipitation of carbides could take place when treated at $650{ }^{\circ} \mathrm{C}$. However, the carbides were too tiny to be detected in this study. That is because the precipitation of carbides is a diffusion-controlled process and the metallic alloying elements cannot diffuse sufficiently during TF testing process. Therefore, the precipitation of secondary carbides should be counted as an important factor for the increase in hardness. (iv) Still, the fine grains along with cell-like substructures and high dislocation concentration are generally deemed as the main reason for the increased mechanical properties in the as-built SLM processed steels [38]. Therefore, the dissolution of cell-like substructures may lead to a decrease of hardness to some degree. (v) During TF testing, the dislocation density might decrease because of the high temperature, while increase because of the fast cooling speed. (vi) The hardness decreases when the hard martensite transforms into soft ferrite and globular carbides when the H13 materials are treated for a long time at elevated temperatures [6,43]. In conclusion, the first three factors and the precipitation of carbides are the main reasons for secondary hardening in the As-SLMed H13. Whereas, the last three factors led to the slightly decrease of hardness.

For the T-SLMed H13, the increase of the hardness within 500 cycles should be mainly attributed to the further diffusion of heavy elements into the matrix during TF testing. However, the hardness began to decrease after more cycles of testing. As illustrated by Meng et al. [6] that no noticeable change was observed in the martensite structures of the laser treated H13 after 4000 cycles of TF testing at $600{ }^{\circ} \mathrm{C}$, while the martensite structures gradually coarsened when increasing the test temperature. Therefore, longer TF testing at $650{ }^{\circ} \mathrm{C}$ led to the softening of the matrix and the decrease of hardness. 

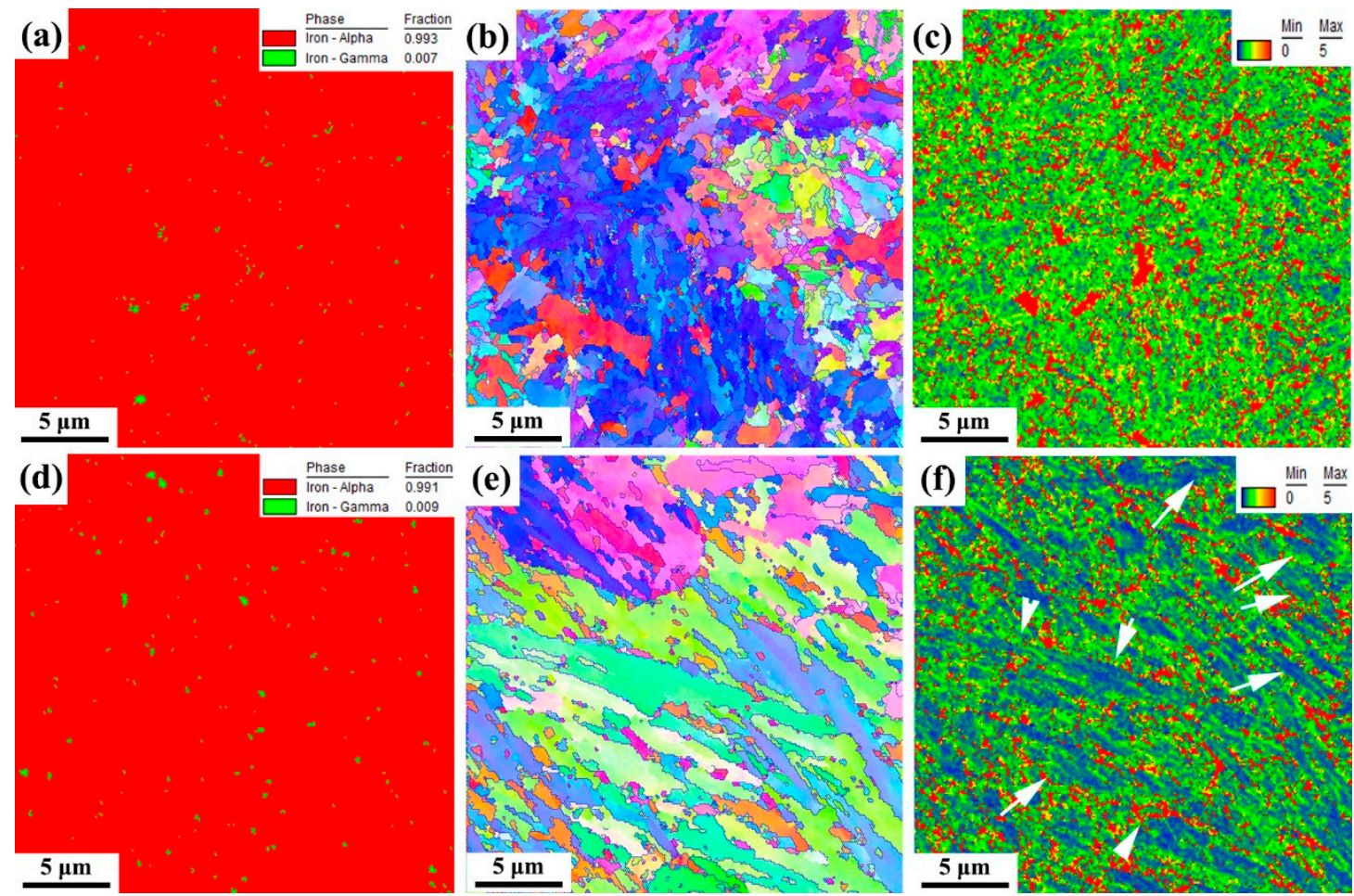

Figure 9. Results that after TF tests. (a-c) are the phase distribution image, inverse pole figure (IPF) image, and Kernel average misorientation (KAM) images of the As-SLMed H13, respectively. (d-f) are the SEM image, IPF image, and KAM image of the Forged H13, respectively.

\subsection{TF Cracking Characteristics}

It is known that the TF cracking of $\mathrm{Cr}-\mathrm{Mo}-\mathrm{V}$ alloyed hot-work dies is determined by the stress-strain-temperature-time loadings and the environmental effects [44]. In the present study, the stress-strain-temperature-time loadings and the environmental effects were the same. Besides, all the three materials possessed a similar initial hardness. As illustrated earlier that the As-SLMed H13 has a higher amount of Si and $\mathrm{Cr}$, and a lower amount of Mo than the Forged H13, it should have inferior resistance to TF. However, TF tests revealed that the As-SLMed H13 possessed an improved resistance to TF. Therefore, microstructures of the As-SLMed and Forged H13 that after TF tests were investigated to reveal the reasons.

\subsubsection{The Effect of Retained Austenite}

Retained austenite is soft and prone to plastic deformation, so it can improve the toughness and ductility of materials [32]. During the crack propagation process, pileup occurs when dislocations move to the grain boundaries, which leads to stress concentration and crack initiation at the beginning of the accumulated pileup. The coherent or semicoherent interfaces between the retained austenite and martensite matrix reduce the resistance to dislocation movement; this reduction softens the material and decreases the crack initiation and propagation rate [45]. Furthermore, a strain-induced transformation of the retained austenite to martensite at the crack tip occurs apparently creates compressive residual stresses that lead to crack closure [46]. Therefore, the TF resistance properties should be improved by increasing the amount of the easily deformed retained austenite. However, retained austenite only functions at the early stage of the TF tests since it decreased substantially after the TF tests. As shown in Figure 9a,d, little amount of retained austenite was detected in the As-SLMed and Forge H13 after TF tests. 


\subsubsection{The Effect of Block Size}

The strength and toughness of martensitic steels are strongly dependent on the size, shape, and arrangement of the packets, blocks, and laths [40]. Among these substructures, the block is known as the most effective type of grain for the strength and impact properties of lath martensite because of its large misorientation at the grain boundary [47]. Therefore, the martensitic block size of the As-SLMed and Forged H13 after TF were analyzed. Generally, misorientations larger than $10.5^{\circ}$ were used to identify the block boundaries [40]. The inverse pole figure (IPF) of Figure $9 \mathrm{~b}$ reveals that the As-SLMed H13 exhibited a fine martensitic microstructure, and the calculated average block size was approximately $1.7 \mu \mathrm{m}$. The Forged $\mathrm{H} 13$ exhibited a coarse martensitic microstructure with an average block size of approximately $3.5 \mu \mathrm{m}$ (Figure 9e), which was twice the size of the As-SLMed H13. Therefore, the toughness of the martensitic steels was supposed to be improved as the grain size was refined [47]. This is because the refined grain size can increase the length of the high-angle grain boundaries (boundaries of prior austenite, packets, blocks, or laths), which are strengthened by dislocation pileup and have the ability to impede the propagation of cleavage cracks [32]. The level of the stress concentration at the crack tip can be estimated by $K_{I C}$ (the fracture toughness of the material) and is expressed by the following equation [48]:

$$
K_{I C}=\left[c\left(\pi \frac{s a_{e}}{a+s}\right)^{\frac{1}{2}}\right]\left(\sigma_{0 y}+k_{y} d^{-\frac{1}{2}}\right),
$$

where $c$ is a numerical constant; is the lattice frictional stress; $k_{y}$ is an experimental constant; $s$ is the width of the crack tip; and $d$ is the grain diameter. Apparently, the $K_{I C}$ increases as $d$ decreases and the material strength increases.

\subsubsection{The Effect of Coarse Laths}

Since the tempered martensite also plays an important role in toughness [49], Kernel average misorientation (KAM) maps were used to evaluate the content of the tempered martensite in the tested materials. The mean value of the KAM was obtained according to the following equation [49]:

$$
\rho=2 v / \mu b
$$

where $\rho$ is the dislocation density; $\mu$ is the unit length; $b$ is the Burgers vector; and $v$ is the mean value of the KAM (rad). According to Equation (3), an increased $v$ indicates an increased $\rho$ when $\mu$ and $b$ are fixed; that is, an increased KAM value indicates an increased dislocation density. Since dislocation pile-ups result in an increase in elastic strain energy [50], the increased KAM value indicates the increased stored energy in the grains [51]. Therefore, the As-SLMed H13 after TF tests possessed a higher level of stress concentration (with an average KAM value of 2.08, as shown in Figure 9c) than that of the Forged H13 (with an average KAM of 1.62, as shown in Figure 9f). The blue areas marked with white arrows in Figure 9c,f represent the tempered martensite. These tempered martensites are generally referred to as coarse laths, which possess pronounced slip activity [49]. Therefore, an increased amount of coarse laths in Forged H13 can improve the toughness of the material.

\subsubsection{The Effect of Cell-Like Substructures}

Cell-like substructures in the as-built H13 that processed by SLM are deemed as segregated substructures that are rich in heavy alloying elements and contain high density dislocations [13]. It is known that high density dislocations can delay crack propagation. Besides, cell-like substructures exhibit high resistance to elevated temperature. Meng et al. [6] revealed that the cell-like substructures of laser treated $\mathrm{H} 13$ dissolved gradually into the matrix with increasing of testing temperature, and remained the morphology after TF tests at $750{ }^{\circ} \mathrm{C}$. Furthermore, the dissolution of cell-like 
substructures into the matrix can lead to an increase of the lattice spacing and hardness. Therefore, cell-like substructures can improve the TF properties of SLM processed H13.

In conclusion, the retained austenite, smaller block size, and cell-like substructures resulted in increased hardness in the As-SLMed H13 during TF tests, which should be the main reasons for the slower TF crack growth obtained in the material compared to the Forged H13. This is also in accordance with the current studies. Mellouli et al. [26] revealed that TF resistance is closely related to the initial hardness, and the increases in the hardness lead to decreases in the crack growth rate. Besides, Jia et al. [25] indicated that the fine grains, increased hardness, and laser melting tracks decelerated the crack propagation in the laser melting zone. However, other factors including residual stresses, dislocation density, porosity, and inclusions can all exert some effects on crack propagation. Strengthening mechanisms like solid solution strengthening and dispersion strengthening can also benefit the TF resistance properties. It is also reported that high strength at room and elevated temperatures, good temper resistance properties, and good resistance to oxidation and structural changes at elevated temperatures are important factors to obtain good resistance to TF $[26,30,50,52]$.

\section{Conclusions}

In this study, microstructural observations and $\mathrm{TF}$ tests $\left(650{ }^{\circ} \mathrm{C} / 30^{\circ} \mathrm{C}\right)$ were carried out on the As-SLMed, T-SLMed, and Forged H13. The major findings are summarized as follows.

(1) The As-SLMed H13 was composed of retained austenite and martensite along with a high density of dislocations. Cell-like substructures were homogeneously distributed in the matrix. The Forged H13 was composed of martensite and carbides.

(2) The hardness of all the tested specimens was set at the level of approximately $597 \mathrm{HV}_{5}$ before the tests. After TF tests, the As-SLMed and T-SLMed H13 showed secondary hardening properties, whereas the Forged H13 showed some softening behavior.

(3) The As-SLMed H13 showed secondary hardening properties should be mainly attributed to the dissolution of the cell-like substructures into the matrix, the transformation of the retained and soft austenite into the hard martensite, and the precipitation of carbides during TF testing.

(4) After TF tests, the As-SLMed H13 exhibited the shortest total crack length, while the Forged H13 exhibited the longest total crack length. These results proved that increased hardness can decelerate the crack propagation.

(5) Microstructural investigation revealed that the increased amount of retained austenite, typical cell-like substructures, and refined grain size in the As-SLMed H13 were the main reasons for the increased TF resistance of the material compared to the Forged H13.

Data availability Statement: The raw data required to reproduce these findings are available to download from (https://doi.org/10.6084/m9.figshare.10261022).

Author Contributions: Conceptualization, methodology, investigation, resources, formal analysis and writing—original draft preparation, M.W.; validation, writing-review and editing, Y.W.; supervision, Y.S.; project administration, funding acquisition, Q.W. All authors have read and agreed to the published version of the manuscript.

Funding: This research was funded by the Science and Technology Major Project of Guangdong Province, No. 2017B090911007, Fundamental Research Funds for the Academic Frontier Youth Team of Huazhong University of Science and Technology; Wuhan Science and Technology Project, No.2018010401011281.

Acknowledgments: The authors would also like to thank the State key Laboratory of Materials Processing and Mould Technology, and the Analysis and Testing Center of Huazhong University of Science and Technology.

Conflicts of Interest: The authors declare no conflict of interest. The funders had no role in the design of the study; in the collection, analyses, or interpretation of data; in the writing of the manuscript, or in the decision to publish the results. 


\section{References}

1. Bartlett, J.L.; Li, X. An overview of residual stresses in metal powder bed fusion. Addit. Manuf. 2019, 27, 131-149.

2. Kruth, J.-P.; Vandenbroucke, B.; Vaerenbergh, V.J.; Mercelis, P. Benchmarking of different SLS/SLM processes as rapid manufacturing techniques. In Proceedings of the International Conference on Polymers and Moulds Innovations (PMI), Gent, Belgium, 20-23 April 2005.

3. Kruth, J.-P.; Schueren, B.V.D.; Bonse, J.E.; Morren, B. Basic powder metallurgical aspects in selective metal powder sintering. CIRP Ann. 1996, 45, 183-186. [CrossRef]

4. Wilson-Heid, A.E.; Qin, S.; Beese, A.M. Anisotropic multiaxial plasticity model for laser powder bed fusion additively manufactured Ti-6Al-4V. Mater. Sci. Eng. A 2018, 738, 90-97. [CrossRef]

5. Hao, L.; Dadbakhsh, S. Materials and process aspects of selective laser melting of metals and metal matrix composites: A review. J. Chin. Laser 2009, 12, 3192-3203. [CrossRef]

6. Meng, C.; Zhou, H.; Zhou, Y.; Gao, M.; Tong, X.; Cong, D.; Wang, C.; Chang, F.; Ren, L. Influence of different temperatures on the thermal fatigue behavior and thermal stability of hot-work tool steel processed by a biomimetic couple laser technique. Opt. Laser Technol. 2014, 57, 57-65. [CrossRef]

7. Armillotta, A.; Baraggi, R.; Fasoli, S. SLM tooling for die casting with conformal cooling channels. Int. J. Adv. Manuf. Technol. 2014, 71, 573-583. [CrossRef]

8. Eric, D. Design considerations of conformal cooling channels in injection mould tools design: An overview. J. Therm. Eng. 2015, 1, 627-635.

9. Huber, F.; Bischof, C.; Hentschel, O.; Heberle, J.; Zettl, J.; Nagulin, K.Y.; Schmidt, M. Laser beam melting and heat-treatment of 1.2343 (AISI H11) tool steel-microstructure and mechanical properties. Mater. Sci. Eng. A 2019, 742, 109-115. [CrossRef]

10. Petrovic, V.; Vicente Haro Gonzalez, J.; Jorda Ferrando, O.; Delgado Gordillo, J.; Ramon Blasco Puchades, J.; Portoles Grinan, L. Additive layered manufacturing: Sectors of industrial application shown through case studies. Int. J. Prod. Res. 2011, 49, 1061-1079. [CrossRef]

11. Hölker, R.; Jäger, A.; Khalifa, N.B.; Tekkaya, A.E. Controlling heat balance in hot aluminum extrusion by additive manufactured extrusion dies with conformal cooling channels. Int. J. Precis. Eng. Manuf. 2013, 14, 1487-1493. [CrossRef]

12. Sander, J.; Hufenbach, J.; Giebeler, L.; Wendrock, H.; Kühn, U.; Eckert, J. Microstructure and properties of FeCrMoVC tool steel produced by selective laser melting. Mater. Des. 2016, 89, 335-341. [CrossRef]

13. Wang, M.; Li, W.; Wu, Y.; Li, S.; Cai, C.; Wen, S.; Wei, Q.; Shi, Y.; Ye, F.; Chen, Z. High-temperature properties and microstructural stability of the AISI H13 hot-work tool steel processed by selective laser melting. Metall. Mater. Trans. B 2019, 50, 531-542. [CrossRef]

14. Deirmina, F.; Peghini, N.; AlMangour, B.; Grzesiak, D.; Pellizzari, M. Heat treatment and properties of a hot work tool steel fabricated by additive manufacturing. Mater. Sci. Eng. A 2019, 753, 109-121. [CrossRef]

15. Mertens, R.; Vrancken, B.; Holmstock, N.; Kinds, Y.; Kruth, J.-P.; Van Humbeeck, J. Influence of powder bed preheating on microstructure and mechanical properties of H13 tool steel SLM parts. Phys. Procedia 2016, 83, 882-890. [CrossRef]

16. Dörfert, R.; Zhang, J.; Clausen, B.; Freiße, H.; Schumacher, J.; Vollertsen, F. Comparison of the fatigue strength between additively and conventionally fabricated tool steel 1.2344. Addit. Manuf. 2019, 27, 217-223. [CrossRef]

17. Lakso, P.; Riipinen, T.; Laukkanen, A.; Andersson, T.; Jokinen, A.; Revuelta, A.; Ruusuvuori, K. Optimization and simulation of SLM process for high density H13 tool steel parts. Phys. Procedia 2016, 83, 26-35. [CrossRef]

18. Ren, B.; Lu, D.; Zhou, R.; Li, Z.; Guan, J. Preparation and mechanical properties of selective laser melted H13 steel. J. Mater. Res. 2019, 34, 1415-1425. [CrossRef]

19. Kurzynowski, T.; Stopyra, W.; Gruber, K.; Ziolkowski, G.; Kuznicka, B.; Chlebus, E. Effect of scanning and support strategies on relative density of SLM-ed H13 steel in relation to specimen size. Materials 2019, 12, 239. [CrossRef]

20. Holzweissig, M.J.; Taube, A.; Brenne, F.; Schaper, M.; Niendorf, T. Microstructural characterization and mechanical performance of hot work tool steel processed by selective laser melting. metall. Mater. Trans. B 2015, 46, 545-549. [CrossRef] 
21. Åsberg, M.; Fredriksson, G.; Hatami, S.; Fredriksson, W.; Krakhmalev, P. Influence of post treatment on microstructure, porosity and mechanical properties of additive manufactured H13 tool steel. Mater. Sci. Eng. A 2019, 742, 584-589. [CrossRef]

22. Pinkerton, A.J.; Li, L. Direct additive laser manufacturing using gas- and water-atomised H13 tool steel powders. Int. J. Adv. Manuf. Technol. 2004, 25, 471-479. [CrossRef]

23. Chen, C.; Wang, Y.; Ou, H.; Lin, Y.-J. Energy-based approach to thermal fatigue life of tool steels for die casting dies. Int. J. Fatigue 2016, 92, 166-178. [CrossRef]

24. Starling, C.M.D.; Branco, J.R.T. Thermal fatigue of hot work tool steel with hard coatings. Thin Solid Films 1997, 308, 436-442. [CrossRef]

25. Jia, Z.-X.; Liu, Y.-W.; Li, J.-Q.; Liu, L.-J.; Li, H.-L. Crack growth behavior at thermal fatigue of H13 tool steel processed by laser surface melting. Int. J. Fatigue 2015, 78, 61-71. [CrossRef]

26. Mellouli, D.; Haddar, N.; Köster, A.; Ayedi, H.F. Hardness effect on thermal fatigue damage of hot-working tool steel. Eng. Fail. Anal. 2014, 45, 85-95. [CrossRef]

27. Persson, A.; Hogmark, S.; Bergström, J. Thermal fatigue cracking of surface engineered hot work tool steels. Surf. Coat. Technol. 2005, 191, 216-227. [CrossRef]

28. Tong, X.; Dai, M.-J.; Zhang, Z.-H. Thermal fatigue resistance of H13 steel treated by selective laser surface melting and CrNi alloying. Appl. Surf. Sci. 2013, 271, 373-380. [CrossRef]

29. Yan, J.J.; Zheng, D.L.; Li, H.X.; Jia, X.; Sun, J.F.; Li, Y.L.; Qian, M.; Yan, M. Selective laser melting of H13: Microstructure and residual stress. J. Mater. Sci. 2017, 52, 12476-12485. [CrossRef]

30. Sjöström, J.; Bergström, J. Thermal fatigue testing of chromium martensitic hot-work tool steel after different austenitizing treatments. J. Mater. Process. Technol. 2004, 153, 1089-1096. [CrossRef]

31. Delagnes, D.; Lamesle, P.; Mathon, M.H.; Mebarki, N.; Levaillant, C. Influence of silicon content on the precipitation of secondary carbides and fatigue properties of a $5 \% \mathrm{Cr}$ tempered martensitic steel. Mater. Sci. Eng. A 2005, 394, 435-444. [CrossRef]

32. ASM International Handbook Committee. ASM Handbook. Volume 1: Properties and Selection: Irons, Steels, and High. Performance Alloys; ASM International: Novelty, OH, USA, 1996.

33. Gwon, H.; Kim, J.-K.; Shin, S.; Cho, L.; De Cooman, B.C. The effect of vanadium micro-alloying on the microstructure and the tensile behavior of TWIP steel. Mater. Sci. Eng. A 2017, 696, 416-428. [CrossRef]

34. Bhadeshia, H.K.D.H.; Honeycombe, R. Steels: Microstructure and Properties, 3rd ed.; Butterworth-Heinemann: Oxford, UK, 2006.

35. Afkhami, S.; Dabiri, M.; Alavi, S.H.; Björk, T.; Salminen, A. Fatigue characteristics of steels manufactured by selective laser melting. Int. J. Fatigue 2019, 122, 72-83. [CrossRef]

36. Henry, B.W.; Bragg, W.L. The reflection of X.-rays by crystals, P. Roy. Soc. Lond. Ser. A 1913, 88, 428-438.

37. Dilip, J.J.S.; Ram, G.D.J.; Starr, T.L.; Stucker, B. Selective laser melting of HY100 steel: Process parameters, microstructure and mechanical properties. Addit. Manuf. 2017, 13, 49-60. [CrossRef]

38. Saeidi, K.; Gao, X.; Lofaj, F.; Kvetková, L.; Shen, Z.J. Transformation of austenite to duplex austenite-ferrite assembly in annealed stainless steel 316L consolidated by laser melting. J. Alloys Comp. 2015, 633, 463-469. [CrossRef]

39. ASM International Handbook Committee. ASM Handbook. Volume 4: Heat Treating; ASM International: Novelty, OH, USA, 1990.

40. Kitahara, H.; Ueji, R.; Tsuji, N.; Minamino, Y. Crystallographic features of lath martensite in low-carbon steel. Acta Mater. 2006, 54, 1279-1288. [CrossRef]

41. Berecz, T.; Jenei, P.; Csóré, A.; Lábár, J.; Gubicza, J.; Szabó, P.J. Determination of dislocation density by electron backscatter diffraction and X-ray line profile analysis in ferrous lath martensite. Mater. Charact. 2016, 113, 117-124. [CrossRef]

42. Zhang, P.; Li, S.X.; Zhang, Z.F. General relationship between strength and hardness. Mater. Sci. Eng. A 2011, 529, 62-73. [CrossRef]

43. Medvedeva, A.; Bergström, J.; Gunnarsson, S.; Andersson, J. High-temperature properties and microstructural stability of hot-work tool steels. Mater. Sci. Eng. A 2009, 523, 39-46. [CrossRef]

44. Klobčar, D.; Tušek, J.; Taljat, B. Thermal fatigue of materials for die-casting tooling. Mater. Sci. Eng. A 2008, 472, 198-207. [CrossRef]

45. Hao, K.; Gong, M.; Pi, Y.; Zhang, C.; Gao, M.; Zeng, X. Effect of Ni content on rolling toughness of laser-arc hybrid welded martensitic stainless steel. J. Mater. Process. Technol. 2018, 251, 127-137. [CrossRef] 
46. Koyama, M.; Zhang, Z.; Wang, M.; Ponge, D.; Paabe, D.; Tsuzaki, K.; Noguchi, H.; Tasan, C.C. Bone-like crack resistance in hierarchical metastable nanolaminate steels. Science 2017, 355, 1055-1057. [CrossRef] [PubMed]

47. Li, S.; Zhu, G.; Kang, Y. Effect of substructure on mechanical properties and fracture behavior of lath martensite in 0.1C-1.1Si-1.7Mn steel. J. Alloys Comp. 2016, 675, 104-115. [CrossRef]

48. Stonesifer, F.R.; Armstrong, R.W. Effect of Prior Austenite Grain Size on the Fracture Toughness Properties of A533 Steel; ICF4: Waterloo, Canada, 1977.

49. Morsdorf, L.; Jeannin, O.; Barbier, D.; Mitsuhara, M.; Raabe, D.; Tasan, C.C. Multiple mechanisms of lath martensite plasticity. Acta Mater. 2016, 121, 202-214. [CrossRef]

50. ASM International Handbook Committee. ASM Handbook. Volume 19: Fatigue and Fracture; ASM International: Novelty, OH, USA, 1996.

51. AlMangour, B.; Grzesiak, D.; Yang, J.-M. Nanocrystalline TiC-reinforced H13 steel matrix nanocomposites fabricated by selective laser melting. Mater. Des. 2016, 96, 150-161. [CrossRef]

52. Hawryluk, M. Review of selected methods of increasing the life of forging tools in hot die forging processes. Arch. Civ. Mech. Eng. 2016, 16, 845-866. [CrossRef]

(C) 2020 by the authors. Licensee MDPI, Basel, Switzerland. This article is an open access article distributed under the terms and conditions of the Creative Commons Attribution (CC BY) license (http://creativecommons.org/licenses/by/4.0/). 